Document downloaded from:

http://hdl.handle.net/10251/51381

This paper must be cited as:

Vincent Vela, MC.; Alvarez Blanco, S.; Lora García, J.; Carbonell Alcaina, C.; Sáez Muñoz, M. (2014). Application of several pretreatment technologies to a wastewater effluent of a petrochemical industry finally treated with reverse osmosis. Desalination and Water Treatment. 1-9. doi:10.1080/19443994.2014.939866.

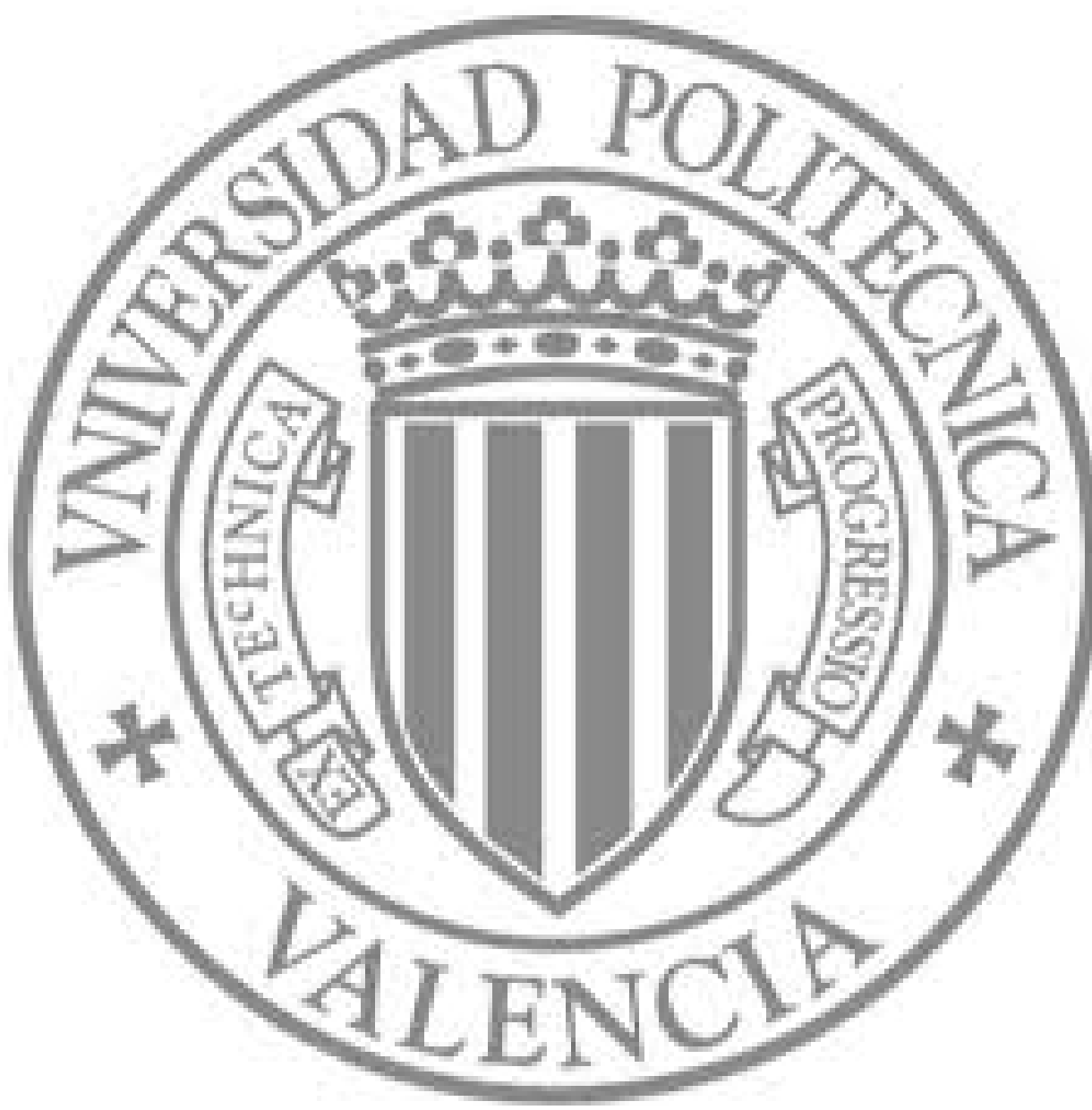

The final publication is available at

http://dx.doi.org/10.1080/19443994.2014.939866

Copyright Taylor \&amp;amp; Francis: STM, Behavioural Science and Public Health Titles 


\section{Application of several pretreatment technologies to a wastewater effluent of a petrochemical industry finally treated with reverse osmosis.}

M.C. Vincent-Vela*, S. Álvarez-Blanco, J. Lora-García, C. Carbonell-Alcaina, M. Sáez Muñoz. Department of Chemical and Nuclear Engineering, Universitat Politècnica de València.

C/Camino de Vera s/n 46022 Valencia, Spain

Tel. +34 963877000 Ext. 79387, Fax +34 963877639

*Corresponding author: mavinve@iqn.upv.es

\section{ABSTRACT}

This work studies the adequacy of different reverse osmosis pretreatments applied to different petrochemical wastewater effluents. Three effluents from a caprolactam factory were analyzed: ion exchange resin washing effluent, batch reactor washing effluent and factory outlet effluent. Coagulation-flocculation, microfiltration and ultrafiltration were tested as reverse osmosis pretreatments. Various inorganic coagulants (Aluminum Chloride, Iron (III) Chloride, Aluminum Sulfate and Polyaluminum Chloride), commercial coagulants (Nophos and ACO) and commercial flocculants (polyacrylamide, $\mathrm{CH}-30$ and APF) were tested at different dosages and stirring speeds. The highest removal of suspended solids and the lowest turbidity were obtained for the ion exchange resin washing effluent. Two combinations of coagulants and flocculants were chosen as the most suitable conditions for the coagulation flocculation process. The ion exchange resin washing effluent was further treated with a combination of microfiltration followed by ultrafiltration. Suspended Solids were completely removed and turbidity decreased to 0.136 NTU. The Silt Density Index at 15 minutes was reduced to 6.41.

Keywords: petrochemical wastewater; reverse osmosis pretreatment; coagulation-

flocculation; ultrafiltration; microfiltration

\section{Introduction}

Nowadays, the importance of wastewater reclamation is increasing due to water scarcity. Industries are the largest water consumers. Water consumptions are around $29 \mathrm{~m}^{3} /$ ton for paper industries, $100 \mathrm{~m}^{3} /$ ton for dying industries, $8 \mathrm{~m}^{3} /$ ton for sugar industries, etc. [1].

Moreover, industries produce polluted wastewaters with a high content of hazardous chemicals. In the petrochemical industry, polyaromatic hydrocarbons (PAHs) and heterocyclic compounds are very common [2]. These effluents are often treated altogether. However, 
effluents from different processes can be reclaimed separately. Sometimes this results in a better reclamation performance. In the present work, effluents from different processes in a petrochemical company were considered to be recovered separately.

Reverse Osmosis (RO) is a suitable technology for wastewater reclamation since it achieves high water quality production. It can be used for petrochemical wastewater reclamation [1-3]. RO water can be used in the factory for cooling, fire-extinction, irrigation, etc.

However, the application of RO and other membrane technologies is limited by membrane fouling processes. Fouling causes permeate flux decline, it decreases process efficiency and it increases costs. Several studies attempt to identify what type of compounds produce severe membrane fouling [4]. However, it is sometimes difficult to identify all the pollutants in a wastewater effluent because of the large amount of compounds that are present. Petrochemical effluents present a wide variability in their composition and physico-chemical parameters ( $\mathrm{pH}$, conductivity and $\mathrm{COD})$. Benito-Alcázar et al. [2] confirmed this variability with a similar petrochemical wastewater effluent to that used in this work.

When fouling occurs, membrane cleaning becomes necessary. Reversible fouling can be removed with water; however, irreversible fouling can only be removed with chemical agents. Chemicals may damage the membrane surface. Moreover, cleaning and changing membranes is expensive.

Different technologies are used as RO pretreatments to avoid premature membrane fouling. RO membrane manufacturers and other authors recommend a turbidity value lower than 1 NTU and a Silt Density Index at 15 minutes $\left(\mathrm{SDI}_{15}\right)$ value lower than 5 . However, $\mathrm{SDI}_{15}$ values lower than 3 are preferred for successful operation [5]. In the case of the SDI at 5 minutes $\left(\mathrm{SDI}_{5}\right)$, a value lower than 15 is recommended. These values can be achieved with different pretreatment methods such as chemical oxidation, granular activated carbon (GAC) filtration, chemical coagulation-flocculation, electrocoagulation, microfiltration (MF), ultrafiltration (UF), nanofiltration (NF), ultraviolet disinfection, etc. Lora et al. [1] suggested the use of a combined UF and NF pretreatment to reuse wastewater in a petrochemical industry whereas BenitoAlcázar et al. [2] proposed to use GAC filtration. Gare et al. proposed physical and chemical pretreatment methods for RO systems [6].

Coagulation-flocculation is widely used as a pretreatment in industrial wastewater treatments. Garg et al. [7] used coagulation-flocculation with diluted black liquor from a pulp and paper 
mill, Verma et al. [8] applied it to a petrochemical wastewater, Garrote et al. [9] used it with tannery effluents and Santo et al. [10] used it in a refinery.

The most common coagulants in industrial and municipal wastewater treatment are inorganic compounds (metal-salts of aluminum, iron, etc). In this research, metal salts were used because of their high effectiveness and low cost $[7,8,10-16]$. Other authors used organic coagulants, such as natural gums, in the pretreatment of petrochemical wastewater [8].

The most widely used flocculants are polyelectrolytes. They can be cationic, anionic or nonionic. Cationic polymers work well on negatively charged colloids and flocs whilst anionic polymers work well on positively charged particles. Non-ionic polymers perform better than charged polymers on uncharged particles and sludge. The use of one or another flocculant depends on the type of wastewater to be treated. Guida et al. [16] used an anionic polyelectrolyte for municipal wastewater whereas Verma et al. [8] used a cationic polyacrylamide for petrochemical wastewater. Rennola et al. [14] employed anionic and cationic polyacrylamides in the vinasses treatment as well as Wang et al. [13] did with a pulp mill wastewater.

Petrochemical industries produce high amounts of polluted wastewaters with hazardous petrochemical compounds. Reverse osmosis technology manages to produce a high quality water stream suitable for reutilization. Traditionally, contaminated streams are mixed and treated altogether. In this paper we propose to treat them separately to achieve high pollutant removal efficiencies. We study several reverse osmosis pretreatments applied to three different petrochemical effluents from a caprolactam production factory: an ion exchange resin washing effluent, a batch reactor washing effluent and the factory outlet effluent. This last effluent results from mixing all factory wastewater effluents. In this research a coagulation-flocculation process was combined with MF and UF to obtain a suitable feed effluent for a RO process. This sequence of coagulation-flocculation and MF or UF has been used in other industrial and municipal wastewater pretreatments [12, 16-19]. However; it has not been applied to petrochemical wastewater effluents. There are other membrane technologies, such as NF, but they require more energy consumption than UF or MF. These are only employed when UF is not feasible.

The effectiveness of a coagulation-flocculation process depends on the type of coagulant and flocculant, their concentrations and the $\mathrm{pH}$ of the wastewater. Usually, these parameters are empirically determined. The tests performed in this work aim to identify the most effective 
coagulant and flocculant for each type of effluent within a petrochemical industry. In addition the best dosages and stirring speeds were determined.

\section{Materials and methods}

\subsection{Effluent characterization}

Three wastewater effluents from a caprolactam factory were considered: ion exchange resin washing effluent (RWE), batch reactor washing effluent (BRE) and factory outlet effluent (OE).

During effluent characterization, conductivity, $\mathrm{pH}$, suspended solids (SS), turbidity and Chemical Oxygen Demand (COD) were determined. For that purpose, standard methods were used [20-23]. Suspended solids (SS) were determined using the standard method UNE-EN 872 [20] with cellulose acetate filters with a pore size of $0.45 \mu \mathrm{m}$. The turbidity was estimated according to UNE-EN ISO 7027 [21].

The Silt Density Index (SDI) is a parameter that measures membrane fouling potential of a RO feed. It was determined using cellulose acetate filters with a pore size of $0.45 \mu \mathrm{m}$ and at a pressure of $207 \mathrm{kPa}$, according to ASTM D4189-07 [22]. The SDI can be estimated as shown in Eq.1. Where $t_{i}$ is the initial time in minutes required to collect $500 \mathrm{~mL}$ of filtrate and $t_{f}$ is the final time in minutes required to collect $500 \mathrm{~mL}$ of filtrate after test time (t). Test time can be 5,10 or 15 minutes.

$$
S D E_{t}=\frac{\left(1-\frac{t_{t}}{t_{f}}\right) \cdot 100}{t}
$$

\subsection{Chemical coagulation and flocculation}

Coagulation-flocculation was applied to the three effluents considered in this work. The samples were prefiltered with a filter of $80 \mu \mathrm{m}$ pore diameter. The best coagulant and flocculant concentrations and stirrer speeds were determined to achieve high removal of SS and turbidity.

Common inorganic coagulants were used, e.g. Aluminum Chloride $\left(\mathrm{AlCl}_{3}\right)$, Iron (III) Chloride $\left(\mathrm{FeAl}_{3}\right)$, Aluminum Sulphate $\left(\mathrm{Al}_{2}\left(\mathrm{SO}_{4}\right)_{3}\right)$ and Polyaluminum Chloride (PACl), all provided by Panreac (Spain). Verma et al. [8] used aluminum and ferric salts with petrochemical wastewater, Garg et al. [7] did it with diluted black liquor, Rossini et al. [14] and Garrote et al. [9] used them with wastewater effluents from a tannery industry and Petrov et al. [17] used 
them with wastewater effluents from a textile industry. Aluminum Chloride was used in a pulp mill industry by Wang et al. [11], Aluminum and Ferric Sulfate in a petroleum refinery by Santo et al. [10], Polyaluminum Chloride in the treatment of distillery wastewaters (vinasses) by Rennola et al. [12] and other inorganic coagulants in the treatment of municipal wastewater [14-16].

Commercial coagulants (Nophos and Active Catalytic Oxidation coagulant (ACO)) for wastewater treatment were also tested. Nophos (Dryden Aqua Ltd, Edinburgh) consisted of a dilute solution containing lanthanum salts, EDTA, cerium salts, activated alumina and an UV stabilizer. It acted as a coagulant as well as a flocculant. ACO (Dryden Aqua Ltd, Edinburgh) consisted of a solution containing activated polysilicates and titanium dioxide nanoparticles.

The flocculants tested were polyacrylamide (PAM), $\mathrm{CH}-30$ and Active Polyfloc (APF). PAM is a commercial anionic flocculant. $\mathrm{CH}-30$ is a commercial cationic flocculant. APF (Dryden Aqua Ltd, Edinburgh) consisted of a mixture of inorganic coagulants and flocculants such as aluminum salts, EDTA, lanthanum salts and an UV stabilizer. Santo et al. [10] used similar flocculants with a petroleum refinery effluent, such as NALCO 71408, a high molecular weight polyacrylamide. Other authors used other anionic and cationic flocculants $[8,11,12,14]$. These authors studied which were the best coagulants and flocculants for petrochemical industry effluents. They tested different concentrations and stirring speeds in Jar-tests [23].

The coagulation-flocculation process was performed using a standard Jar-test (ASTM D203580) [23]. Beakers of $1 \mathrm{~L}$ were used in the coagulation step and Imhoff cones of $1 \mathrm{~L}$ were used in the flocculation step.

In the coagulation step, the wastewater sample and the coagulant were placed in $1 \mathrm{~L}$ beakers with a mechanical mixing device. The flocculant was added to that mixture and it was mixed. The final sample volume was $900 \mathrm{~mL}$. After that, it was transferred to a $1 \mathrm{~L}$ Imhoff cone. In the final step, the flocs were allowed to settle for $30 \mathrm{~min}$. The parameters analyzed were the settled volume and the turbidity of the clarified liquid.

For the inorganic coagulants tested, the range of concentrations tested was from 200 to 700 $\mathrm{ppm}$. This range is commonly employed for wastewater effluents from industries with similar values of SS, turbidity or COD to the ones reported in this study. Petrov et al. [17] used concentrations ranging from 100 to $500 \mathrm{mg} / \mathrm{L}$ with a textile wastewater to remove basic colors from water; Garrote et al. [9] tested concentrations in the range of 100 to $200 \mathrm{ppm}$ with a 
tannery effluent and Guida et al. [14] used concentrations ranging from 150 to $450 \mathrm{ppm}$ with municipal wastewater. For commercial coagulants, manufacturers recommended dosages of 1$2 \mathrm{~mL}$ diluted to $10 \%$ [24]. The flocculant content was lower than that of coagulant. The range of dosages used for flocculants is around $2 \mathrm{ppm}[10,14]$. For commercial flocculants, $0.5-1 \mathrm{~mL}$ diluted to $10 \%$ were used, according to the manufacturer [24]. In the literature, concentrations around 20 ppm were used for highly polluted effluents $[8,11,12]$.

The stirring speeds tested were in the range of 100 to $270 \mathrm{rpm}$ for the coagulation step. On the other hand, flocculation required slow mixing. In this case, speeds of 30-50 rpm were used for 15 minutes. Settling time in Imhoff cones was 30 minutes. These conditions were similar to those employed by other authors in coagulation-flocculation processes [8, 11, 13-15].

It is recommended to adjust the solution $\mathrm{pH}$ by adding chemicals such as $\mathrm{H}_{2} \mathrm{SO}_{4} / \mathrm{HCl}$ and $\mathrm{NaOH}$ to optimize the flocculation process $[8,11,13,15]$. In this work, $\mathrm{pH}$ was adjusted to achieve high SS and turbidity removal.

When the best conditions were determined, coagulation-flocculation processes were performed for each effluent. The final clarified effluent was analyzed to evaluate its suitability for RO feeding. SS, turbidity, COD and $\mathrm{SDI}_{15}$ were measured.

\subsection{Microfiltration and ultrafiltration}

MF followed by UF was used for the clarified stream of the RWE obtained in the coagulationflocculation process. Microfiltration and ultrafiltration was performed according to the standard method ASTM D7285-06 [25]. Previously, liable flocs in the clarified stream were removed by pre-filtration with a $20 \mu \mathrm{m}$ filter cartridge.

The experimental set-up for MF and UF was described in detail by Benito-Alcázar et al. [2]. Firstly, microfiltration with two membranes with a pore size of $0.25 \mu \mathrm{m}$ was carried out. Polyvinylidene fluoride membranes (PVDF) were provided by Orelis Environment. The MF was performed at a transmembrane pressure $(\Delta \mathrm{P})$ of $1.5 \cdot 10^{5} \mathrm{~Pa}$ and a cross-flow velocity of $1 \mathrm{~m} / \mathrm{s}$. The total volume treated was $23.5 \mathrm{~L}$ and the duration of the experiment was $15 \mathrm{~h}$.

UF membranes of polyethersulfone (PES) were provided by Orelis Environment. Their MWCOs were 100 and $500 \mathrm{kDa}$. The experiment was performed at a transmembrane pressure of $1.5 \cdot 10^{5} \mathrm{~Pa}$ and a cross-flow velocity of $1 \mathrm{~m} / \mathrm{s}$. The total volume treated was $19 \mathrm{~L}$ and the duration of the experiment was $3.5 \mathrm{~h}$. 
Permeate flux was measured and permeate and retentate samples were collected every $0.5 \mathrm{~h}$ for sample characterization (conductivity, $\mathrm{pH}, \mathrm{SS}$, turbidity, COD and $\mathrm{SDI}_{15}$ ).

\section{Results and discussion}

\subsection{Effluent characterization}

The values of the characterization parameters (average values and range) of the three effluents considered in this work are shown in Table 1. The characterization results for the three effluents considered in this work are highly different from each other. This suggests that they should be treated separately.

Table 1. Effluent characterization: Average values and range. (RWE: ion exchange resin washing effluent; BRE: batch reactor washing effluent; OE: factory outlet effluent.)

\begin{tabular}{cccc}
\hline Parameter & RWE & BRE & OE \\
\hline Conductivity $(\mu \mathrm{S} / \mathrm{cm})$ & $207[62.7-413.0]$ & $3120[2120-4640]$ & $5890[3760-7890]$ \\
$\mathrm{pH}$ & $8.14[4.12-11.10]$ & $11.80[11.66-11.99]$ & $7.99[7.69-8.28]$ \\
$\mathrm{SS}(\mathrm{mg} / \mathrm{L})$ & $8.67[2-16]$ & $641.33[124-1664]$ & $46[16-76]$ \\
Turbidity (NTU) & $2.10[0.073-6.95]$ & $202.36[54.89-497.25]$ & $13.10[5.89-20.30]$ \\
COD (mg/L) & $14598[6285-27929]$ & - & 92 \\
\hline
\end{tabular}

The average turbidity value of the RWE was much lower than that of the other effluents. The same occurred with the values of conductivity and SS. However, in the SS tests, cellulose acetate filters were blocked in few minutes. This suggested that pollutants may form a gel layer structure. RWE was slightly basic on average $(\mathrm{pH}=8.14)$. Nevertheless, this effluent had fluctuating $\mathrm{pH}$ values. These values were sometimes highly acid $(\mathrm{pH}=4)$. Therefore, the coagulation process was expected to be completely affected, owing to the fact that the effectiveness of coagulants depends on the $\mathrm{pH}$ of the wastewater effluent. Besides, RWE presented a heavy organic load $(C O D=14598 \mathrm{mg} / \mathrm{L})$. This was due to the fact that most common pollutants of the RWE were of organic nature (hydrocarbons, lubricating oils and organic fibers).

The BRE presented the highest content in suspended solids $(641.33 \mathrm{mg} / \mathrm{L})$ and the greatest turbidity (202.36 NTU). BRE was basic, with an average $\mathrm{pH}$ of 11.80 .

The OE presented the highest conductivity $(5890 \mu \mathrm{S} / \mathrm{cm})$. This suggested a high content of ionic compounds from inorganic nature in the OE. The organic content (COD=92 mg/L) was 
very low and it had the best values to release in the sewage system (COD $<125 \mathrm{mg} / \mathrm{L}$ ) according to regulating agencies prescription [8]. Suspended solids and turbidity values were in between RWE and BRE.

It should be noted that $\mathrm{SDI}_{15}$ could not be measured for any of the three effluents due to their high fouling potential. Therefore, it was necessary a suitable pretreatment before feeding these effluents to a RO process.

\subsection{Determination of the best conditions for the coagulation and flocculation process}

\subsection{1 lon exchange resin washing effluent (RWE)}

Experiments using Aluminum Chloride and Iron Chloride in combination with $\mathrm{CH}-30$ did not produce any precipitate volume. This may be due to the significant decrease in the $\mathrm{pH}$ when the coagulant was added. From a slightly basic $\mathrm{pH}(8-9)$, it decreased to a highly acid $\mathrm{pH}(3-4)$. In the literature [26], the optimum $\mathrm{pH}$ values for aluminum and ferric salts at $25 \stackrel{\circ}{ } \mathrm{C}$ with a dissolved solids concentration of $140 \mathrm{mg} / \mathrm{L}$ are 5.32 and 8.2, respectively. Hence, RWE conditions were not suitable for these coagulants.

Aluminum Sulfate and Polyaluminum Chloride at different concentrations and stirring speeds were used in combination with PAM at $2 \mathrm{ppm}$ and different stirring speeds. The results are shown in Table 2. In the case of Aluminum Sulfate, neither coagulation stirring speeds (Css), nor flocculation stirring speeds (Fss) had a significant influence on the sedimentation volume in 30 minutes $\left(\mathrm{V}_{30}\right)$. The mean value of $\mathrm{V}_{30}$ was $43.22 \mathrm{~mL}$ and the standard deviation was 0.88 . For Polyaluminum Chloride the higher the $\mathrm{PACl}$ concentration was, the greater sedimentation volumes were obtained. Low stirring speeds for flocculation were suitable for this effluent. Delgado et al. [15] evaluated the influence of PACl concentration on turbidity removal for municipal wastewater. They found that the higher the PACl concentration was, the greater turbidity removal was achieved (for $\mathrm{pH}$ values between 5 and 9). Moreover, $\mathrm{PACl}$ removal results were better than those of Aluminum Sulfate and Iron Chloride. Santo et al. [10] obtained similar results with a petroleum refinery effluent. An increase of $80 \mathrm{mg} / \mathrm{L}$ in the coagulant dosage produced an increase of $40 \%$ in the turbidity removal efficiency. Therefore, the best conditions for RWE with common inorganic coagulants and PAM as flocculant were: $[P A C l]=700 \mathrm{ppm}, \mathrm{Css}=220 \mathrm{rpm} ;[\mathrm{PAM}]=2 \mathrm{ppm}, \mathrm{Fss}=30 \mathrm{rpm}$. 
Table 2. RWE: Sedimentation volume in 30 minutes $\left(V_{30}\right)$ using $2 \mathrm{ppm}$ of PAM as a flocculant.

\begin{tabular}{ccccc}
\hline Coagulant & Cc (ppm) & Css (rpm) & Fss (rpm) & $V_{30}(\mathrm{~mL})$ \\
\hline \multirow{4}{*}{$\mathrm{Al}_{2}\left(\mathrm{SO}_{4}\right)_{3}$} & 200 & 100 & 30 & 42.67 \\
& 200 & 100 & 40 & 42.67 \\
& 200 & 100 & 50 & 43 \\
& 200 & 200 & 30 & 42.33 \\
& 200 & 200 & 40 & 44.33 \\
& 200 & 200 & 50 & 44.33 \\
\hline \multirow{6}{*}{$\mathrm{PACl}$} & 100 & 180 & 50 & 7.67 \\
& 300 & 180 & 50 & 27.67 \\
& 500 & 180 & 50 & 48 \\
& 700 & 180 & 50 & 78 \\
& 700 & 220 & 30 & 88.67 \\
& 700 & 220 & 50 & 78 \\
\hline
\end{tabular}

The coagulation-flocculation results for commercial coagulants are shown in Table 3 . In this case, the low density of flocs prevented them from precipitating. Therefore, turbidity was considered instead of $\mathrm{V}_{30}$. The results show that Nophos did not achieve any turbidity removal (Tables 1 and 3). ACO and APF results were similar at different dosages. Consequently, for ACO and APF the best conditions in terms of turbidity removal were: $A C O=1 \mathrm{~mL}$ (diluted to $10 \%$ ), Css $=180 \mathrm{rpm}$ and $\mathrm{APF}=1 \mathrm{~mL}$ (diluted to $10 \%$ ), Fss $=50 \mathrm{rpm}$.

Table 3. RWE: Turbidity at 30 minutes of the clarified stream for a Css of $180 \mathrm{rpm}$.

\begin{tabular}{cccccc}
\hline Coagulant & Flocculant & $\mathrm{Cv}(\mathrm{mL})$ & $\mathrm{Fv}(\mathrm{mL})$ & Fss (rpm) & Turbidity (NTU) \\
\hline \multirow{4}{*}{ Nophos } & & 0.05 & 0.05 & 50 & 4.793 \\
& \multirow{2}{*}{ Nophos } & 0.1 & 0.1 & 30 & 8.387 \\
& & 0.1 & 0.1 & 40 & 8.463 \\
& & 0.1 & 0.1 & 50 & 21.233 \\
ACO & APF & 0.2 & 0.2 & 40 & 27.209 \\
\hline & & 0.1 & 0.1 & 50 & 0.262 \\
\end{tabular}

\subsubsection{Batch reactor washing effluent (BRE)}

Table 4 shows the sedimentation volumes obtained for different stirring speeds, $200 \mathrm{ppm}$ of Aluminum Sulfate and $2 \mathrm{ppm}$ of PAM. Coagulation and flocculation stirring speeds did not have any significant influence on the precipitated volumes. An increase in Fss at the highest Css tested resulted in a slight increase in the precipitated volume. The opposite occurred for the lowest Css tested. The best conditions were those that corresponded to the lowest energy 
consumption: $\left[\mathrm{Al}_{2}\left(\mathrm{SO}_{4}\right)_{3}\right]=200 \mathrm{ppm}, \mathrm{Css}=100 \mathrm{rpm}$; $[\mathrm{PAM}]=2 \mathrm{ppm}, \mathrm{Fss}=30 \mathrm{rpm}$. However, the flocs were small, they had a low density and its settling speeds were very slow.

Table 4. BRE: Sedimentation volume in 30 minutes $\left(\mathrm{V}_{30}\right)$ for $200 \mathrm{ppm}$ of $\mathrm{Al}_{2}\left(\mathrm{SO}_{4}\right)_{3}$ and $2 \mathrm{ppm}$ of PAM.

\begin{tabular}{ccc}
\hline Css (rpm) & Fss (rpm) & $\mathrm{V}_{30}(\mathrm{~mL})$ \\
\hline \multirow{2}{*}{100} & 30 & 51.33 \\
& 40 & 48.00 \\
& 50 & 44.00 \\
\hline \multirow{2}{*}{200} & 30 & 44.67 \\
& 40 & 49.00 \\
& 50 & 50.33 \\
\hline
\end{tabular}

\subsubsection{Factory outlet effluent (OE)}

For the $\mathrm{OE}$, the coagulation-flocculation results for a flocculant dosage of $2 \mathrm{ppm}$ are shown in Table 5.

Table 5. OE: Sedimentation volume in $\mathbf{3 0}$ minutes $\left(\mathrm{V}_{30}\right)$ for a flocculant concentration of 2 ppm.

\begin{tabular}{cccccc}
\hline Coagulant & Flocculant & Cc (ppm) & Css (rpm) & Fss (rpm) & $\mathrm{V}_{30}(\mathrm{~mL})$ \\
\hline \multirow{2}{*}{$\mathrm{AlCl}_{3}$} & \multirow{2}{*}{$\mathrm{CH}-30$} & 200 & 180 & 50 & 21.95 \\
& & 500 & 180 & 50 & 37.92 \\
& & 700 & 180 & 50 & 107.53 \\
\hline \multirow{2}{*}{$\mathrm{FeCl}_{3}$} & \multirow{2}{*}{$\mathrm{CH}-30$} & 200 & 180 & 50 & 31.83 \\
& & 500 & 180 & 50 & 78.01 \\
& & 700 & 180 & 50 & 83.87 \\
\hline \multirow{4}{*}{$\mathrm{PACl}$} & & 500 & 100 & 30 & 46 \\
& \multirow{2}{*}{ PAM } & 500 & 100 & 40 & 44.67 \\
& & 500 & 100 & 50 & 43 \\
& & 500 & 270 & 30 & 46.33 \\
& & 500 & 270 & 40 & 43.83 \\
& & 500 & 270 & 50 & 41.33 \\
\hline
\end{tabular}

It can be observed that, at equal coagulant concentrations, iron chloride sludge volumes were higher than those of aluminum chloride, except in the case of the highest coagulant concentration tested. In that case, flocs density was lower and the flocs floated instead of precipitating. Similar results were obtained by Haberkamp et al. [16] and Petrov et al. [17]. They reported lower sedimentation volumes for $\mathrm{AlCl}_{3}$ than in the case of $\mathrm{FeCl}_{3}$. Moreover, the settling volume of iron was more compact and it decanted faster. Although higher flocculant 
dosages (4 ppm) were tested, this resulted in even a lower density of the flocs than in the case of $2 \mathrm{ppm}$ of flocculant concentration. Furthermore, the higher coagulant dosage added, the greater sludge volume obtained. In this way, the best conditions selected when $\mathrm{CH}-30$ was used as a flocculant were: $\left[\mathrm{FeCl}_{3}\right]=700 \mathrm{ppm}, \mathrm{Css}=180 \mathrm{rpm},[\mathrm{CH}-30]=2 \mathrm{ppm}, \mathrm{Fss}=50 \mathrm{rpm}$. When PAM was used as an anionic flocculant and PACl was used as a coagulant, the stirring speeds of coagulation and flocculation did not exert a high influence on sludge volumes.

Therefore, in the case of PAM and PACl, turbidity was chosen to estimate the best stirring speed conditions (Table 6). It was noticed that the higher the coagulation stirring speed was, the lower turbidity of the clarified stream was achieved. The lowest turbidity value was obtained for the following experimental conditions: $[\mathrm{PACl}]=500 \mathrm{ppm}, \mathrm{Css}=270 \mathrm{rpm} ;[\mathrm{PAM}]=$ $2 \mathrm{ppm}, \mathrm{Fss}=50 \mathrm{rpm}$.

Table 6. OE: Turbidity of the clarified stream for $500 \mathrm{ppm}$ of PACl and $2 \mathrm{ppm}$ of PAM.

\begin{tabular}{ccc}
\hline Css (rpm) & Fss (rpm) & Turbidity (NTU) \\
\hline 100 & 30 & 5.339 \\
100 & 40 & 5.694 \\
100 & 50 & 4.714 \\
270 & 30 & 2.638 \\
270 & 40 & 1.774 \\
270 & 50 & 0.910 \\
\hline
\end{tabular}

\subsubsection{Effluent analysis after the coagulation-flocculation process}

The best coagulation-flocculation process conditions selected for each effluent are shown in Table 7.

Table 7. Best coagulation-flocculation process conditions for each effluent considered.

\begin{tabular}{ccccccc}
\hline Effluent & Coagulant & Flocculant & Cc (ppm) & Css (rpm) & Fc (ppm) & Fss (rpm) \\
\hline RWE & $\mathrm{PACl}$ & PAM & 700 & 200 & 2 & 30 \\
& $\mathrm{ACO}$ & APF & $0.1^{\text {a }}$ & 180 & $0.1^{\mathrm{a}}$ & 50 \\
\hline $\mathrm{BRE}$ & $\mathrm{Al}_{2}\left(\mathrm{SO}_{4}\right)_{3}$ & $\mathrm{PAM}$ & 2 & 100 & 2 & 30 \\
\hline $\mathrm{OE}$ & $\mathrm{FeCl}_{3}$ & $\mathrm{CH}-30$ & 700 & 180 & 2 & 50 \\
& $\mathrm{PACl}$ & PAM & 500 & 270 & 2 & 50 \\
\hline
\end{tabular}

${ }^{a}$ These values correspond to the flocculant volume added in $\mathrm{mL}$. 
For the RWE and PACI-PAM, the turbidity of the clarified stream was 0.109 NTU and its removal efficiency was 9.92\%. The COD value was $6255 \mathrm{mg} / \mathrm{L}$ (removal efficiency of 1.26\%). The amount of SS was $2 \mathrm{mg} / \mathrm{L}$ (removal efficiency of 50\%). Delgado et al. [15] achieved higher reductions in turbidity $(80 \%)$ due to the lesser pollution of municipal wastewater and Santo et al. [10] also achieved high turbidity reductions with higher anionic flocculant concentrations ( $4.5 \mathrm{mg} / \mathrm{L})$. For RWE and ACO-APF the turbidity value was 0.262 NTU. It was a similar value to that of PACl-PAM. Moreover, the $\mathrm{pH}$ of the clarified stream in both cases was close to a neutral value, 6.67 and 7.02, respectively. In this way, both combinations were feasible to pretreat the RWE.

For the BRE, the effluent contained a high initial amount of suspended solids (1664 mg/L). The pretreatment with a $80 \mu \mathrm{m}$ filter and the Jar-tests were not effective to reduce the concentration of suspended solids. For this reason, this wastewater effluent was not considered suitable for RO feeding.

For the $\mathrm{OE}$, the following combinations were selected: $\mathrm{FeCl}_{3}-\mathrm{CH}-30$ and PACl-PAM. In the first case, the removal efficiency of SS and turbidity was $0 \%$. Thus, this coagulation-flocculation process was not effective because it did not improve wastewater conditions. For $\mathrm{PACl}$ and PAM, SS and turbidity were partially removed. However, COD and $\mathrm{pH}$ values remained almost equal. The clarified stream had a SS value of $12 \mathrm{mg} / \mathrm{L}$ and a turbidity value of $0.114 \mathrm{NTU}$, with removal efficiencies of $75 \%$ and $99.63 \%$, respectively. The COD value was $74 \mathrm{mg} / \mathrm{L}$ with a removal efficiency of $2.63 \%$. In the case of vinasse, Rennola et al. [12] obtained different values using PACl-PAM. They achieved a $30 \%$ of turbidity removal with cationic PAM. In the case of the $\mathrm{OE}$, anionic flocculants were more effective, owing to colloids having positive charges whereas in the vinasse colloids had negative charges.

In all the experiments of sample characterization after coagulation-flocculation processes, the $\mathrm{SDI}_{15}$ could not be measured due to the fact that the $0.45 \mu \mathrm{m}$ microfilter was blocked after few minutes of filtering.

\subsection{Microfiltration and ultrafiltration}

MF and UF tests were performed for the RWE since it had the most suitable characteristics for RO feeding after the coagulation-flocculation process. 
In the MF tests (Fig.1), permeate flux $\left(J_{p}\right)$ scarcely decreased over time, i.e. membrane fouling was negligible. However, permeate flux decline was significant for both UF membranes (Fig. 2). The rate of permeate flux decline was similar in both cases: $23.25 \%$ in $3 \mathrm{~h}$ for the $500 \mathrm{kDa}$ UF membrane and $21.93 \%$ in $3 \mathrm{~h}$ for the $100 \mathrm{kDa}$ UF membrane.

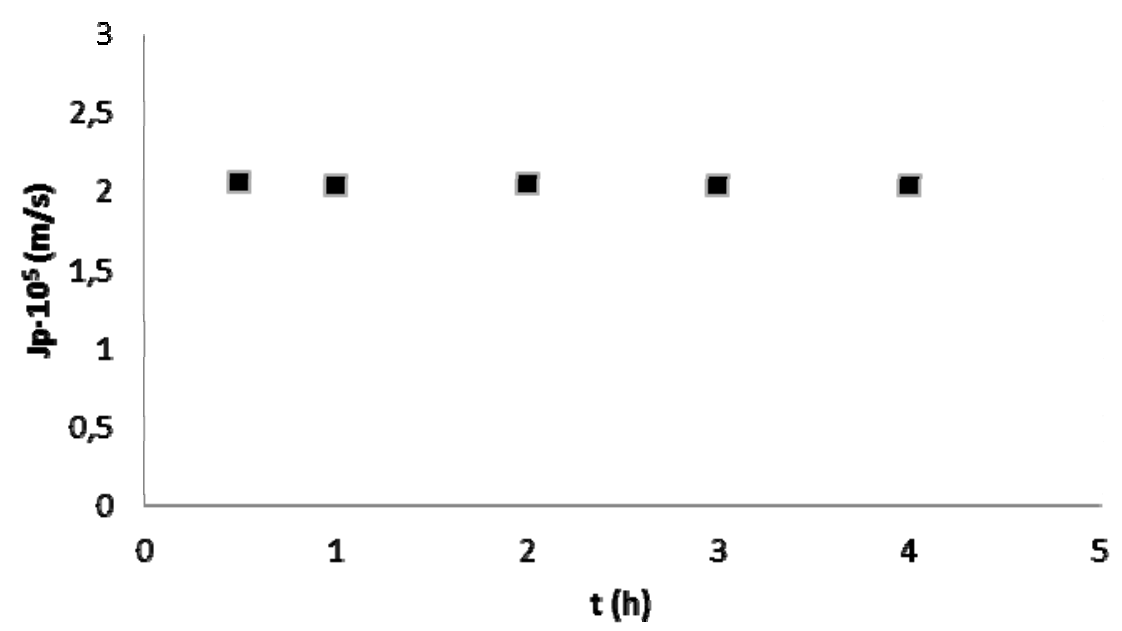

Figure 1. $\mathrm{J}_{\mathrm{p}}$ vs. time for MF membranes of $0.25 \mu \mathrm{m}$.

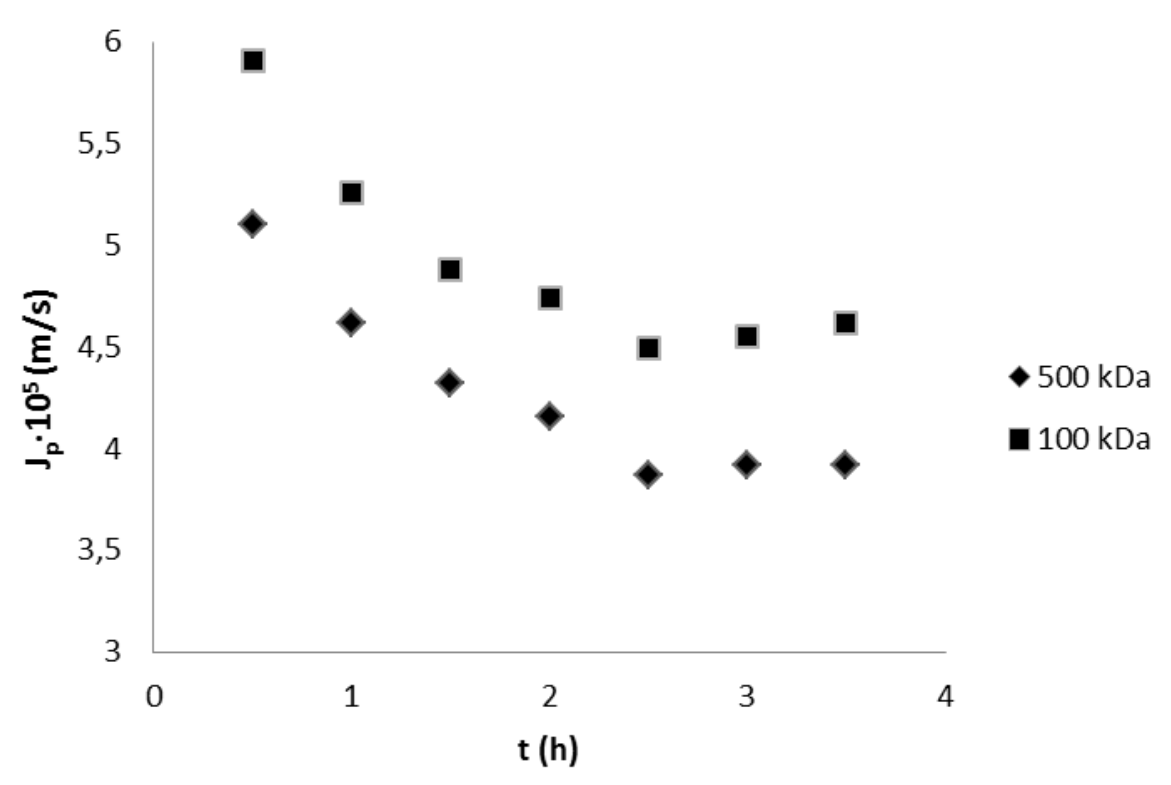

Figure $2 . \mathrm{J}_{\mathrm{p}}$ vs. time for UF membranes of $500 \mathrm{kDa}$ and $100 \mathrm{kDa}$ MWCO.

MF and UF permeate characterization is shown in Table 8. MF achieved a $33.33 \%$ of removal efficiency for SS whereas UF achieved a $100 \%$ of removal efficiency for SS for the two 
membranes tested. For turbidity and COD, a $0 \%$ of removal efficiency was achieved for both MF and UF tests. Lora et al. also achieved low COD removal percentages (4\%) with membranes of 0.2 and $0.05 \mu \mathrm{m}$ pore diameter [1].

Table 8. Permeate stream characterization

\begin{tabular}{cccc}
\hline Membrane & SS (mg/L) & Turbidity (NTU) & COD (mg/L) \\
\hline MF $(0.25 \mu \mathrm{m})$ & 4 & 0.105 & 9540 \\
UF (500 kDa) & 0 & 0.136 & 9600 \\
UF (100 kDa) & 0 & 0.136 & 9620 \\
\hline
\end{tabular}

The SDI was measured for the UF permeate streams (Table 9). The SDI ${ }_{5}$ was below the value of 20 for both UF permeate streams. However, it was above 15, the value suggested by RO manufacturers and other authors [5]. The same occurred with the SDI ${ }_{15}$. Although its value was near to the value suggested by authors $\left(\mathrm{SDI}_{15}<5\right)$, it was above this value.

\section{Table 9. SDI for UF permeate stream}

\begin{tabular}{ccc}
\hline Membrane & $\mathrm{SDI}_{5}$ & $\mathrm{SDI}_{15}$ \\
\hline UF (500 kDa) & 17.89 & $>6.67$ \\
UF (100 kDa) & 18.16 & 6.41 \\
\hline
\end{tabular}

\section{Conclusions}

Ion exchange resins washing effluent (RWE) was the most suitable effluent to reclaim and reuse in the factory. In this work, an improvement in the characteristics of the RWE was achieved by removing a large amount of pollutants. However, after the treatment of coagulation-flocculation coupled with MF-UF, an effluent with a $\mathrm{SDI}_{15}$ value above that recommended for RO feeding was achieved.

For RWE, the most suitable combinations for the coagulation-flocculation process were: $A C O=$ $1 \mathrm{~mL}$ (diluted to $10 \%$ ), Css $=180 \mathrm{rpm}$ and $\mathrm{APF}=1 \mathrm{~mL}$ (diluted to $10 \%$ ), Fss=50 rpm. UF experiments removed all the SS present in the RWE, although the $\mathrm{SDI}_{15}$ could only be reduced up to a value of 6.41 .

A coagulation-flocculation process coupled with UF achieved a significant removal of SS, turbidity and COD.

\section{Acknowledgements}


The authors of this work wish to gratefully acknowledge the financial support from the Generalitat Valenciana through the program "Ayudas para la realización de proyectos I+D para grupos de investigación emergentes GV/2013".

\section{Symbols}

ACO - Active Catalytic Oxidation

APF - Active Polyfloc

COD - Chemical Oxygen Demand

$\mathrm{Cc}-$ Coagulant concentration, $\mathrm{ppm}$

Css - Coagulation stirring speed, rpm

$\mathrm{Cv}$ - Coagulant volume, $\mathrm{mL}$

EfOM - Effluent Organic Matter

$\mathrm{Fc}-$ Flocculant concentration, $\mathrm{ppm}$

Fss - Flocculation stirring speed, rpm

$\mathrm{Fv}$ - Flocculant volume, $\mathrm{mL}$

GAC - Granular Activated Carbon

$\mathrm{J}_{\mathrm{p}}$ - Permeate flux, $\mathrm{m} / \mathrm{s}$

MF - Microfiltration

MWCO - Molecular Weight Cut Off

NF - Nanofiltration

$\Delta \mathrm{P}$ - Transmembrane pressure

$\mathrm{PACl}$ - Polyaluminum Chloride

PAHs - Polyaromatic Hydrocarbons

PAM - Polyacrylamide

PES - Polyethersulphone

PVDF - Polyvinylidene fluoride

RO - Reverse Osmosis

$\mathrm{SDI}_{5}$ - Silt Density Index at 5 minutes

$\mathrm{SDI}_{15}$ - Silt Density Index at 15 minutes

SS - Suspended solids

TOC - Total Organic Carbon

UF - Ultrafiltration

$\mathrm{V}_{30}$-Sedimentation volume in 30 minutes, $\mathrm{mL}$ 


\section{References}

[1] J. Lora, D. Sanz, J.M. Gozálvez, A. Santafé, J.M. Arnal, M.C. León, S.Navalón, Ultrafiltration and Nanofiltration Pre-Treatment of Reverse Osmosis to Reuse Wastewater in a Petrochemical Industry, October 21-26, IDA World Congress on Desalination and Water Reuse, Maspalomas, Gran Canaria, Spain 2007, IDAWC REF: (MP07-232).

[2] C.Benito-Alcázar, M.C. Vincent-Vela, J.M. Gozálvez-Zafrilla, J. Lora-García, Study of different pretreatments for reverse osmosis reclamation of a petrochemical secondary effluent, J. Hazard. Mater. 178; 2010: 883-889.

[3] S.S. Madaeni, M.R. Eslamifard, Recycle unit wastewater treatment in petrochemical complex using reverse osmosis process, J. Hazard. Mater. 174; 2010: 404-409.

[4] H. Kim, B.A. Dempsey, Effects of wastewater effluent organic materials on fouling in ultrafiltration, Water Res. 42; 2008: 3379-3384.

[5] L.K. Wang, J.P. Chen, J. Hung, N.K. Shammas, Membrane and Desalination Technologies, first ed., Humana Press, London, 2011.

[6] S.Gare, RO systems: the importance of pretreatment, Filtration+Separation (January/February 2002) 22-27

[7] A. Garg, I.M. Mishra, S. Chand, Effectiveness of coagulation and acid precipitation processes for the pre-treatment of diluted black liquor, J. Hazard. Mater. 180; 2010: 158-164.

[8] S. Verma, B. Prasad, I.M. Mishra, Pretreatment of petrochemical wastewater by coagulation and flocculation and the sludge characteristics, J. Hazard. Mater. 178; 2010: 10551064.

[9] J.I. Garrote, M. Bao, P. Castro, M. J. Bao, Treatment of tannery effluents by a two step coagulation/flocculation process, Water Res. 29; 1995: 2605-2608.

[10] C.E. Santo, V.J.P. Vilar, C.M.S. Botelho, A. Bhatnagar, E. Kumar, R.A.R. Boaventura, Optimization of coagulation-flocculation and flotation parameters for the treatment of a petroleum refinery effluent from a Portuguese plant, Chem. Eng. J. 183; 2012: 117-123. 
[11] J. Wang, Y. Chen, Y. Wang, S. Yuan, H. Yu, Optimization of the coagulation-flocculation process for pulp mill wastewater treatment using a combination of uniform design and response surface methodology, Water Res. 45; 2011: 5633-5640.

[12] L. Rennola, C.Yépez, J.Bullón, F.Salazar, Treatment of destillery wastewaters using coagulants and membranes, Revista Técnica de la Facultad de Ingeniería. Universidad del Zulia 30 (2007).

[13] M. Rossini, J. García Garrido, M. Galluzzo, Optimization of the coagulation-flocculation treatment: Influence of rapid mix parameters, Water Res. 33; 1999: 1817-1826.

[14] M. Guida, M. Mattei, C. Della Rocca, G. Melluso, S. Meriç, Optimization of alumcoagulation/flocculation for COD and TSS removal from five municipal wastewater, Desalination 211; 2007: 113-127.

[15] S. Delgado, F. Diaz, D.García, N.Otero, Behaviour of Inorganic Coagulants in Secondary Effluents from Conventional Wastewater Treatment Plant, Filtration+Separation (September 2003) 42-43.

[16] J. Haberkamp, A.S. Ruhl, M. Ernst, M. Jekel, Impact of coagulation and adsorption on DOC fractions of secondary effluent and resulting fouling behavior in ultrafiltration, Water Res. 41; 2007: 3794-3802.

[17] S. Petrov, P.A. Stoichev, Reagend Ultrafiltration Purification of Water Contamined with Reactive Dyes, Filtration+Separation (October 2002) 34-38.

[18] H.K. Shon, S. Vigneswaran, H.H. Ngo, R.B. Aim, Is semi-flocculation effective as pretreatment to ultrafiltration in wastewater treatment?, Water Res. 39; 2005: 147-153.

[19] J.W. Hatt, E. Germain, S.J. Judd, Precoagulation-microfiltration for wastewater reuse, Water Res. 45; 2011: 6471-6478.

[20] UNE-EN 872 Water quality. Determination of suspended solids. Method by filtration trough membrane filters.

[21] UNE-EN ISO 7027 Water quality. Determination of Turbidity.

[22] ASTM D4189-07 Standard text method for silt density index (SDI) of water.

[23] ASTM D2035-80 Standard Practice for Coagulation-Flocculation Jar-Test of Water. 
[24] Dryden Aqua Ltd, www.DrydenAqua.com (06-04-13)

[25] ASTM D7285-06 (2010) Standard Guide for Recordkeeping Microfiltration and Ultrafiltration Systems

[26] A. P. Sincero, G.A. Sincero, Physical-chemical treatment of water and wastewater, first ed., IWA Publishing, London, 2002. 